Rev. peru. biol. 2003; 10 (1): 101-108

\title{
HISTOLOGÍA DE LA MACA, LEPIDIUM MEYENII WALPERS (BRASSICACEAE)
}

Manuel Marín-Bravo1

\section{- RESUMEN \\ - DISCUSIÓN}

\section{RESUMEN}

Se presenta el estudio histológico de Lepidium meyenii Walpers "maca", enfocado principalmente en la caracterización del órgano reservante. El estudio se realizó en macas de color amarillo, procedentes de Junín, y comprendió la caracterización histológica del órgano reservante subterráneo y detalles adicionales de la estructura interna foliar, a partir de muestras fijadas en FAA y empleando la técnica de inclusión en parafina.

Los resultados muestran en el órgano reservante las características de una región de transición entre la raíz, de estructura secundaria lignificada, y el tallo primario reducido, con el desarrollo de una amplia zona medular. Presenta además un tipo peculiar de actividad cambial secundaria en la forma de haces conductores corticales. Entre los detalles histológicos adicionales está el desarrollo de una cubierta suberificada de células corticales en el órgano reservante y la presencia de tricomas cónicos unicelulares en las hojas.

Palabras clave: maca, Lepidium, histología vegetal, Perú.

\section{SUMMARY}

The histological study of Lepidium meyenii Walpers "maca" is focused mainly on the characterization of the underground storage organ. The study was carried out with yellow macas from Junín, and it comprises the histological study of the storage organ and additionally details of internal structure of the leaves from samples fixed in FAA and using the inclusion in paraffin technique.

The results show in the storage organ the characteristics of a transitional region among the root of a lignified structure and a reduced primary stem, with the development of a wide medullar area. Additionally, there is a characteristic secondary cambial activity in the cortical area. Likewise, among the additional histological details reported for this plant, is the development of a suberized lining of cortical cells in the storage organ and conical unicellular trichomes in the surface of the leaves.

Key words: maca, Lepidium, Plant Histology, Peru. 
cultiva principalmente en la zona de la meseta de Bombón, en el departamento de Junín, entre los 3700 y 4500 msnm, región que presenta un clima agreste y bajas temperaturas extremas. Conocida y empleada desde los tiempos precolombinos principalmente como una planta medicinal $\mathrm{y} / \mathrm{o}$ alimenticia, la medicina tradicional peruana hace mención de sus principales propiedades como estimulante de la reproducción y energizante o revitalizadora (León, 1964; Tovar, 2001).

Numerosos trabajos han descrito ampliamente la morfología externa de esta planta (León, 1964; Tello et al., 1992; Chacón, 1990; Obregón, 1998). La maca se describe morfológicamente como una planta típica de la puna andina, de porte arrosetado, que presenta una corona de hojas basales que surgen por encima de un eje carnoso en el suelo. El cultivo es considerado bianual y presenta una fase vegetativa en la que se produce el crecimiento y expansión del órgano de reserva y una fase reproductiva, caracterizada por la producción de flores y frutos. Sin embargo, durante los años de condiciones climáticas favorables (ausencia de heladas y abundante humedad) las plantas pueden completar su ciclo reproductivo en un año (Quiroz y Aliaga, 1997).

Desde el punto de vista taxonómico, la maca, única representante de la familia Brassicaceae cultivada en la Puna, fue primeramente determinada como Lepidium meyenii Walpers (Obregón, 1998). Chacón (1990), en una revisión botánica de los ejemplares de maca cultivados en los Andes Centrales, la describió como una especie nueva, Lepidium peruvianum. Al menos siete especies silvestres del género Lepidium han sido reportados para el Perú por Brako y Zarucchi (1993), desde Áncash hasta Puno; asimismo, otras especies de Lepidium han sido colectadas en Ecuador, Bolivia y Argentina. Se sabe muy poco acerca de estas especies y de su posible relación con la maca cultivada; las especies silvestres de Lepidium han mostrado un bajo polimorfismo en estudios de marcadores moleculares (DNA polimórfico amplificado aleatoriamente, RAPD) y por tanto estar alejadas de la maca cultivada (Quiroz y Aliaga, 1997). La verificación de su actual nombre científico requeriría de mayores investigaciones taxonómicas (Quiroz y Aliaga, 1997). Una revisión taxonómica de las especies del género Lepidium existentes en el país podría esclarecer este tema.

Los diferentes autores al referirse al órgano reservante de la planta responsable de las propiedades terapéuticas, lo han descrito unos como hipocótilo (León, 1964; Chacón, 1990; Tello et al., 1992; Quiroz y Aliaga, 1997; Genyi et al., 2001) y otros como raíz (Baquerizo, 1968; Lama et al., 1993; Obregón, 1998). El problema, lejos de ser resuelto, ha sido simplificado al punto de ser considerado agronómicamente como una raíz (Aliaga, 1995; Obregón, 1998). Los trabajos publicados sobre el tema no muestran los detalles histológicos que evidencien claramente la naturaleza anatómica del órgano reservante. El importante aporte realizado por León (1964), en el que da cuenta de características anómalas en el desarrollo de los tejidos no fue revisado apropiadamente (Baquerizo, 1968). Sin embargo, Metcalfe y Chalk (1950) en la revisión de los aspectos anatómicos de la familia Cruciferae (Brassicaceae) revelan detalles histológicos del género Lepidium (e.g. presencia de haces corticales anómalos) que no han sido verificados para la maca. Los estudios botánicos realizados (Obregón, 1998; Chacón, 1990; León, 1964), carecen además de una adecuada evidencia e interpretación de los tejidos, por lo que se requeriria completar el estudio de la estructura interna del órgano reservante.

El presente estudio tiene por objetivo la caracterización histológica del órgano reservante y estructura interna foliar de la planta.

El material colectado (macas amarillas) fue dividido en sus partes apical, media y distal y fijado en FAA (formaldehido, ácido acético glacial y etanol). La inclusión de las muestras en parafina fue llevada a cabo según Marín (1998), para la obtención de cortes seriados transversales y longitudinales, de las partes distal, media y apical. En la coloración y montaje permanente de los cortes se empleó la tinción cuádruple (Johansen, 1940) y Entellan respectivamente. 
Las hojas fueron fijadas en FAA. Se efectuaron secciones transversales y superficiales de las muestras, a nivel de la parte media. Las secciones superficiales fueron aclaradas con hidróxido de potasio 3\% (D'Ambrogio de Argüeso, 1986) y esquematizadas a 100 y 400 aumentos por medio de una Cámara Clara Zeiss. Las secciones transversales fueron aclaradas con hipoclorito de sodio $50 \%$, teñidas con Safranina y montadas temporalmente en glicerina fenicada. Adicionalmente se realizaron cortes transversales al estado fresco de la parte subterránea (1,0 mm de espesor) para la caracterización macroscópica de los tejidos.

\section{Descripción de la estructura interna del órgano reservante}

Vista en sección transversal, la maca presenta en su parte media un característico cilindro vascular central ramificado, en forma de estrella (Fig. 1), rodeado por un cámbium vascular de contorno sinuoso de un encendido color amarillo; hacia el interior los vasos del xilema se disponen radialmente en medio de abundante parénquima reservante mientras la zona floemática, también parenquimatosa, presenta un color opaco frente al xilema. La mayor parte de la estela constituye la zona medular, conformada por células parenquimáticas reservantes de almidón; éstos son de tipo simple, de formas redondeadas o elipsoidales. En la zona medular se registró las mayores dimensiones del almidón así como de las células del parénquima reservante (Tabla 1 ).

En la periferia se aprecia una serie de células ligeramente rectangulares y suberizadas, de las cuales las más externas son de aspecto aplanado y dispuestas en estratos de apariencia desorganizada (Figs. 2 y 3). En ejemplares jóvenes de maca se ha podido apreciar, a nivel de la parte media, una capa epidérmica cutinizada. Las células corticales vecinas presentan paredes engrosadas. Cuando es posible distinguir las células epidérmicas, éstas son de forma ligeramente cuadrada y más grandes que las corticales. No es clara la distinción de un felógeno y más bien las células corticales exteriores presentan un aspecto alargado y aplanado, semejando células suberosas, rectangulares y aplanadas. En macas de color amarillo y morado, la coloración se presenta en éstas células periféricas. Fue positiva la reacción ácido-base para la presencia de antocianinas aplicada en esta zona.

En la zona cortical se observa haces conductores, de aspecto circular (Figs. 3, 4 y 5), con los vasos del xilema dispuestos radialmente hacia el centro mientras que el floema se distingue por su color opaco, opuesto al xilema. Entre ambos se aprecia una delgada capa meristemática de aspecto parecido a un procámbium. Estos haces conductores concéntricos se presentan en toda la zona cortical, especialmente en la zona media y apical, en número de cuatro, cinco o más, y se encuentran ampliamente separados por parénquima reservante (Fig. 1). En las zonas apical y subapical, en contacto con las trazas foliares, se distingue en la parte central una zona medular parenquimatosa, delimitada por vasos del xilema primario (Figs. 6 y 7 ).

En sección longitudinal, se aprecia el contorno aovado del cilindro vascular que va estrechándose en diámetro de la parte superior hasta la zona distal, dejando en ambos lados una amplia zona cortical; varios haces conductores concéntricos particularmente en sus partes media y superior se distinguen principalmente por el aspecto del xilema en cortas bandas longitudinales. El cámbium vascular delimita la zona superior (yema apical) frente a los primordios foliares y florales. En el interior, en la zona medular, los vasos xilemáticos se presentan radialmente dispersos entre las células parenquimáticas reservantes de granos de almidón. Esta zona es delimitada por el cámbium vascular y los vasos primarios del xilema que sin embargo, no lo encierran completamente, sino que permiten a la médula estrecharse gradualmente hacia la zona distal del órgano reservante; en esta zona, paralelamente al estrechamiento de la corteza, el cilindro vascular se reduce por desaparición completa del parénquima medular y su reemplazo por el xilema secundario. A este nivel, los vasos del xilema se presentan contraídos longitudinalmente y presentan una bifurcación en forma de " $Y$ " en el tramo inferior próximo a la zona distal (Fig. 8); de ahí en adelante esta zona presenta las características de una raíz de estructura secundaria, con el xilema completamente lignificado (Fig. 9). 


\section{Descripción de la estructura interna foliar}

En las secciones transversales, las hojas basales de la maca presentan una estructura bifacial, con una gruesa cutícula en su lado adaxial. El parénquima en empalizada se presenta hasta en tres capas celulares y su aspecto no difiere mayormente de las del parénquima esponjoso, que presenta más bien escasos espacios intercelulares. A nivel de la nervadura central, la epidermis presenta células alargadas y orientadas paralelamente, presentando además tricomas cónicos unicelulares de característico recubrimiento cuticular (Figs. 10 y11). La hoja presenta estomas en ambas superficies (anfiestomática) y son mayormente de tipo anisocítico (Fig. 12).

\section{DISCUSIÓN}

Acorde con Metcalfe y Chalk (1950) y León (1964), la raíz primaria de la maca presenta una estela diarca, lo cual determinaría una raíz muy delgada o de escaso grosor en un posterior crecimiento secundario. Por lo general, muchas especies herbáceas de la familia Brassicaceae presentan este tipo de estela (Simonds, 1938). Según Esaú (1959), los mayores diámetros en el desarrollo de la raíz están asociados a estelas de tipo pentarca, hexarcas y heptarcas. Sin embargo es evidente que durante el temprano desarrollo de la maca, se produce en la estela diarca una proliferación importante del parénquima asociado a un orden regular de los tejidos. A diferencia del rabanito (Raphanus sativus) y la zanahoria (Daucus carota), los mayores diámetros alcanzados por el órgano reservante de la maca, son el producto de una constante actividad cambial secundaria, es decir, cámbiumes anómalos de desarrollo posterior al cámbium vascular, que localizados en la corteza son los que determinan una masiva proliferación de parénquima y con ello el mayor grosor del órgano reservante.

Sería difícil afirmar si el órgano reservante es un tallo (hipocótilo) o raíz sin emprender un adecuado estudio de su ontogenia, es decir del proceso de formación del órgano, desde sus estadios iniciales. Probablemente ambos términos aplicados al órgano reservante de la maca son discutibles, dado que el primero sólo es válido cuando se emplea en los primeros estadios de una plántula, mientras que en el segundo no tiene en consideración el porte arrosetado de la planta adulta, y por tanto, que posee una región de tallo, aunque muy reducida, en unión con la raíz. En este tallo, la presencia de una definida zona parenquimatosa en la zona apical representaría la yema apical de una planta acaule, en contacto estrecho con los primordios de hojas y flores. Sin embargo, el contorno del cámbium vascular en la estela, estrechándose desde la zona apical hacia la distal, la presencia de la médula parenquimatosa y los vasos xilemáticos primarios señalan la posibilidad de ser la región de transición entre el tallo y la raíz quien asumiría la mayor parte del engrosamiento del órgano de reserva; la raíz propiamente dicha ocuparía la zona distal del órgano con una típica estructura secundaria. No obstante, en el desarrollo secundario alcanzado, la disposición radial de los vasos xilemáticos junto con la masiva producción de parénquima reservante de almidón harían ver a esta región con la apariencia de una raíz reservante. Es posible señalar puntualmente la transición entre la estela caulinar parenquimatosa de las zonas media y apical y la estela radical completamente lignificada de la zona distal del órgano reservante: desde la zona distal hacia la parte superior del órgano los vasos xilemáticos divergen en dos ramales desde el inicio de la zona engrosada, mostrando entonces la aparición de la zona medular (Fig. 8).

Por otro lado, la presencia de vasos xilemáticos contraídos en el comienzo de la zona distal es característica de una región de transición (Esaú, 1959) y el aspecto arrugado que presenta externamente el órgano reservante es una clara evidencia de la contracción de los tejidos desde un temprano desarrollo. Probablemente durante los estadios iniciales de su crecimiento, la parte superior del eje (hipocótilo) asumiría la mayor parte del engrosamiento como producto de una contracción generalizada de la zona radical; según esto la región de transición en la maca sería mas bien corta (Esaú, 1959). Al mismo tiempo, la temprana aparición de la actividad cambial secundaria en la corteza determinaría la formación de un cuerpo carnoso a escasa profundidad del suelo. Diversos autores consideran hipocótilo a esta región engrosada 
(Genyi et al., 2001; Tello et al., 1992; Quiroz y Aliaga, 1997).

El desarrollo de haces conductores corticales representa un modelo particular de crecimiento anómalo en donde la actividad cambial secundaria se da exclusivamente en la zona cortical del órgano reservante. Este tipo de crecimiento se presenta en tallos y raíces de diversas especies vegetales y generalmente se presenta en el interior de la estela como una variedad de cámbiumes supernumerarios. Sin embargo, los haces vasculares corticales en especies de Brassicaceae han sido reportados sólo para Lepidium latifolium (Metcalfe y Chalk, 1950).

En secciones transversales realizados en plantas de maca cultivadas en la costa y que, sin embargo, no desarrollaron un órgano reservante, ha sido posible observar una disposición similar de los tejidos, con la diferencia de presentar una estrecha zona cortical, sin haces corticales, y más bien la zona medular es amplia en su parte apical; la zona distal presenta el característico desarrollo secundario. Dado el reporte de León (1964) acerca del crecimiento anómalo en la maca desde su temprano desarrollo, es probable que ésta sea favorecida por las condiciones del medio ambiente propio de su hábitat altiplánico.

Por otro lado, la dificultad en observar claramente un felógeno en la cubierta externa de células y la forma y aspecto de las mismas determinaría que se tratase de una epidermis suberificada, conjuntamente con las células corticales primarias que serían empujadas hacia el exterior por el crecimiento secundario y finalmente terminarían por suberificarse. Su finalidad sería la de proporcionar protección externa; esto es típico en plantas herbáceas que no alcanzan un completo desarrollo secundario con formación de peridermis (Esaú, 1959; Quiroz y Aliaga, 1997). Además, estas células presentan una forma diferente de la de una típica célula suberosa y en los ejemplares jóvenes de maca cuya cubierta externa es de color morado, curiosamente presentan un contenido de antocianinas, pigmento que difícilmente se encuentra en una capa suberosa; compuesta por células muertas y que presentan además suberina en sus paredes. Sin embargo, en algunos ejemplares de maca en plena floración, se ha podido observar el desarrollo de una incipiente capa peridérmica por debajo de estas células corticales suberificadas, lo que presumiblemente puede interpretarse como una continuación del desarrollo secundario de los tejidos en esa etapa del desarrollo.

Finalmente, la presencia de los tricomas unicelulares cónicos en la superficie foliar es el primer reporte para esta planta $y$, sin embargo, son usuales este tipo de estructuras en las Brassicaceae (Metcalfe y Chalk, 1950; Simonds, 1938). Asimismo, conforme a lo observado en las hojas de la maca, parece ser característico del género Lepidium la presencia de un mesófilo uniforme, conformado por cortas células parenquimáticas en empalizada y escasa diferencia con el parénquima lagunar (Simonds, 1938). La presencia de idioblastos de mirosina, característicos de la Brassicaceae, no pudo verificarse en las secciones transversales efectuadas.

\section{AGRADECIMIENTOS}

Al Consejo Nacional de Ciencia y Tecnología, CONCYTEC, por el financiamiento de la investigación, y a la Dra. Eleucy Pérez T. por la revisión del manuscrito original.

\section{Bibliografía}

1 Laboratorio de Anatomía y Farmacognosia Vegetal, Facultad de Ciencias Biológicas, Universidad Nacional Mayor de San Marcos, Ciudad Universitaria. Av. Venezuela s/n, Lima 01, Perú.

E-mail: Manuel Marín: mmarinb@unmsm.edu.pe 
